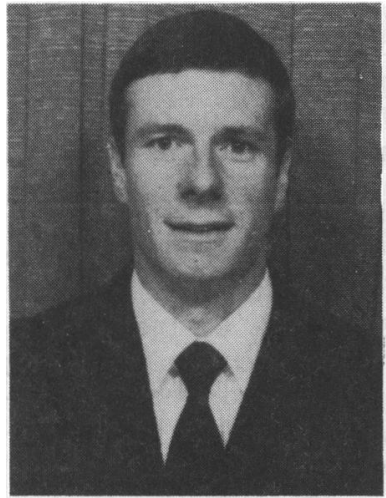

J. A. White

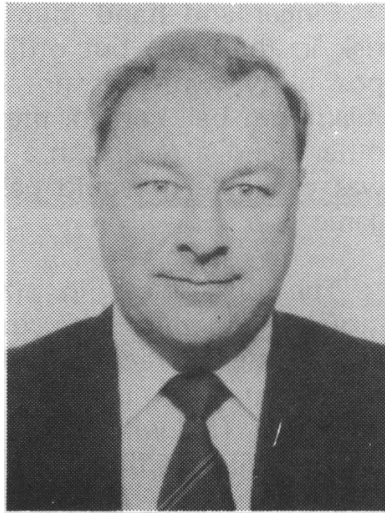

M. A. Ford

\title{
THE CARBOHYDRATE MAINTENANCE PROPERTIES OF AN EXPERIMENTAL SPORTS DRINK
}

\author{
J. A. WHITE, PhD* and M. A. FORD, ARIC, AIFST** \\ ${ }^{*}$ Department of Physical Education and Sciences, West London Institute of Higher Education, \\ Borough Ruad, Isleworth, Middlesex TW7 5DU
}

** Beecham Products, Research and Development Division, The Royal Forest Factory, Coleford, Gloucester GL16 8JB

\begin{abstract}
The effects of an experimental sports drink (Q) were compared with a commercial sports drink (D) of proven ergogenic efficacy. Seven highly trained subjects performed two hours of cycle ergometry exercise at $\sim 65 \%$ maximal aerobic power $\left(\mathrm{VO}_{2} \max \right)$ while receiving levels of $\mathrm{Q}$ and $\mathrm{D}$ in quantities designed to supply approximately $28 \%$ of the total energy requirement of the exercise task. Both $Q$ and $D$ formulations were supplied at 15 minute intervals at $16^{\circ} \mathrm{C}$, in volumes required to provide equivalent carbohydrate loads from two products of differing concentrations and compositions. $Q$ was equally as effective as $D$ in terms of the maintenance of plasma glucose concentrations during exercise, while selected physiological indices of work performance favoured $Q$. However, the time course of plasma glucose concentration changes during and after exercise indicated a trend towards more rapid uptake and assimilation of carbohydrate in the case of $\mathbf{Q}$. The findings suggest that $\mathbf{Q}$ may provide a more readily available carbohydrate source during exercise and may enhance work performance through its ergogenic properties.
\end{abstract}

Key words: Carbohydrate maintenance, Exercise, Cyclists.

\section{INTRODUCTION}

Enhanced work performance capability has been related to pre-event carbohydrate intake (Bergström et al, 1967; Bergström and Hultman, 1972; Brooke, Davies and Green, 1972; Foster, Costill and Fink, 1979) and further influenced by carbohydrate feeding during work activity (Brooke et al, 1972; Brooke and Green, 1973; Brooke, Davies and Green, 1975; Green and Thomas, 1971; Thomas, 1971). Furthermore, carbohydrate availability during recovery from activity may enhance work performance capability on subsequent work bouts (Brooke and Green, 1974; Brooke and Green, 1975).

Glucose-electrolyte solutions administered during prolonged severe exercise appear to enhance the relative availability of the carbohydrate fuel source for energy production (Costill, Kammer and Fisher, 1970; Costill et al, 1973), although the rate of uptake of glucoseelectrolyte solutions is more dependent upon factors related to gastric emptying, including volume, temperature and carbohydrate content (Costill and Saltin, 1974) than on intestinal absorption (Fordtran and Saltin, 1967). Since glucose polymer appears to increase work production during exercise by enhancing carbohydrate utilisation (Ivy et al, 1979), it has been suggested that the mechanism of facilitated work performance, resulting from carbohydrate ingestion 
during prolonged exercise, may be associated with the maintenance of blood glucose homeostasis, which may offset muscle glycogen depletion (Ahlborg and Felig, 1977; Pirnay et al, 1977 a, b). Moreover, evidence exists to support the enhancement of endurance performance as a result of glucose polymer ingestion during exercise (Ivy et al, 1983; Langenfield, 1983) without necessarily incurring any deliterious effects related to reactive hypoglycemia resulting from the ingestion of such compounds (Crapo, Reavan and Olefsky, 1976; Green, 1976).

\section{METHODS}

\section{Subjects}

The subjects used in this study were the same seven individuals who completed the dehydration/rehydration trial series (White and Ford, 1983) and, as such, were thoroughly habituated to the laboratory procedures involved.

\section{Experimental Protocol}

The experimental design utilised for the carbohydrate loading trials consisted of three separate phases:-

Phase 1. The preparatory phase consisted of standardising dietary and exercise habits of the subjects on the days prior to, and, day of, each trial, as well as a $\mathbf{3 0}$ minute rest period immediately before each test.

Phase 2. The experimental phase consisted of two hours of each treatment at an exercise level sustained at approximately $65 \%$ of each subject's previously established aerobic maximum level $\left(\mathrm{VO}_{2}\right.$ max). Cardiorespiratory values were determined at 20 minute intervals to ensure the stability of the physiological levels of work. Capillary blood samples were obtained initially, and at one and two hours of exercise, for the assessment of plasma glucose concentration. Body weight, core (rectal) temperature and fluid (weight) loss estimates were obtained on the same schedule, and five minutes were allowed between the first and second hour of the experiment for each subject to change clothing.

Phase 3. The recovery phase consisted of a one hour recovery period, when the subjects rested in a reclining position, and all relevant data were collected at one half hour and one hour following exercise.

\section{Treatments}

The experimental drink (Q) and the established product (D) were each randomly given to all seven experimental subjects at 15 minute intervals, beginning 30 minutes prior to the onset of the experiment and throughout the duration of the exercise, but were discontinued during the recovery phase. The total energy intake provided was approximately $28 \%$ of the estimated energy requirement of the exercise task. Energy costs of the exercise were estimated, utilising the respiratory findings of the $\frac{0}{\mathrm{c}}$ previous dehydration trial series, together with 3 standardised tabled values of metabolic energy equivalents, as detailed in Table 1 . While the total provision supplied by both formulations $Q$ and $D$ was the same in terms of energy content and estimated percentage contribution to the total energy demand of the exercise task, the total fluid volume supplied varied according to the formulation, as detailed in Table $I$.

\section{TABLE I}

Energy requirement, provision and energy content of fluids during the experimental protocol
Energy Requirement*

Oxygen Consumption (1. $\mathrm{min}^{-1}$ )

Respiratory Exchange Ratio

Non-Protein Conversion Factor

Energy Requirement ( $\mathrm{kJ} \mathrm{min}^{-1}$ )

Energy Requirement (Total kJ)

Energy Provision

Total Fluid Volume (ml)

Product $\mathbf{Q}$

Product D

Product $Q$

\% Total Energy Requirement (D \& Q)

Energy Content Carbohydrate $(\mathrm{kJ} / 100 \mathrm{ml}) \begin{aligned} & \text { Product } D \\ & \text { Product } Q\end{aligned}$

$\begin{array}{ccc}X & \pm & \text { S.E. } \\ 3.30 & & 0.20 \\ 0.84 & & 0.03 \\ 20.3 & & 0.15 \\ 66.8 & & 3.68 \\ 8015.8 & 443.3\end{array}$

390.9

1217.6

2293.1

2293.5

28.4

32.8

102.0

192.1

192.1

1.2

586.0

188.4

(Values represent recommended usage; product $D$ undiluted product $Q-1: 1$ dilution)

"Data estimated from mean respiratory values obtained during the no fluids treatment of the dehydration trial.

This difference resulted from the relative energy contents per unit volume of the established product $D$ (a glucose syrup) and the experimental drink $Q$ (a citrous drink) which were used in undiluted (D) and 1:1 dilution (Q), respectively. The energy contents and electrolyte concentrations of both formulations are presented in Table II. Throughout the carbohydrate loading trial series, fluids were supplied in nine equal volumes for each respective formulation, served from previously prepared thermos flasks at a cold tap water temperature of $16^{\circ} \mathrm{C}$.

Attempts were made to control and standardise both the timing and environmental conditions under which the carbohydrate loading trial series were conducted. Each individual performed the exercise protocol while receiving treatments $Q$ and $D$ on the same day of the week and at the same time of day. Furthermore, a minimum of two weeks' delay was allowed between the two successive treatments for each individual. The internal laboratory environmental conditions were maintained as uniformly as possible (temperature $21^{\circ} \mathrm{C} \pm$

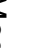




\section{TABLE II}

Electrolyte concentrations and energy content of the experimental drink (Q) and the product (D)

Electrolyte Concentration
$(\mathrm{mg} / 100 \mathrm{ml})$
Sodium
Potassium
Calcium
Magnesium
Chloride
Phosphate

$\begin{array}{cc}\text { Q } & D \\ \text { (Undiluted) } & \\ 250 & 65 \\ 50 & 16 \\ 31 & 28 \\ 5 & - \\ 200 & 70 \\ 125 & 40\end{array}$

Energy Content $(\mathrm{kJ} / 100 \mathrm{ml})$ Carbohydrate

376.7

586.0

$0.5^{\circ} \mathrm{C}$, relative humidity $\left.65 \% \pm 1.5 \%\right)$. In the absence of the normal evaporative cooling effects of cycling under laboratory conditions, during each experiment, subjects exercised in racing attire consisting of racing shorts, socks and cycling shoes only, with supplementary cooling provided by an electric fan directed towards the head and upper body region. Nevertheless, subjects sweated freely in all experiments.

\section{Ergometry}

The ergometry system utilised for the ergogenic study was identical to that described in the dehydration/ rehydration trial series (White and Ford, 1983). The work loads selected for the duration of each experiment were approximately $65 \%$ of each subject's previously determined maximum aerobic power $\left(\mathrm{VO}_{2}\right.$ max) established during the pre-trial tests. Standardised work loads based upon each subject's average power output established during the previous dehydration trial tests were replicated during each of the two fluid treatment $(Q$ and $D)$ trials. The intensity of the work selected was comparable to that of other studies which have demonstrated changes in carbohydrates (glucose) energy provision during prolonged exercise activities.

\section{ANALYSES}

The assessment of the physiological parameters, including cardiovascular, respiratory and body temperature data was carried out using the same techniques as those previously described (White and Ford, 1983).

\section{Plasma Glucose Analysis}

Capillary blood samples were obtained using a fingerprick technique and duplicate samples were analysed for plasma glucose, using a glucose colorimetric method (GOD/Perid Method, Bohringer (BCL) Limited).

\section{Statistical Analysis}

Inferential statistics in the form of a one-tailed $t$ test for correlated data were used to detect differences in treatment effects associated with each trial in terms of the physiological parameters and plasma glucose levels.

\section{RESULTS}

\section{Physiological Changes}

A statistical summary of the major mean physiological changes, associated with the ergogenic trial series, is presented in Table III.

The physiological demands of the exercise, in terms of body weight, body temperature, cardiovascular and respiratory changes, favoured treatment $\mathbf{Q}$ in comparison with treatment $D$. Marked, and often statistically significant, effects were demonstrated by treatment 0 during the exercise, in terms of body weight (fluid) maintenance, heart rate, systolic blood pressure, rate/ pressure product and oxygen consumption. Similar effects were noted during the recovery period, in terms of body weight (fluid) maintenance, body temperature and systolic blood pressure. This indicated that both the magnitude of physiological disturbance during exercise was minimised via reduced work effort and the return to pre-exercise levels was enhanced in the case of treatment $Q$.

\section{Plasma Glucose Changes}

A statistical summary of the major mean plasma glucose changes is presented in Table IV.

The plasma glucose changes observed, in terms of the magnitude of disturbance from pre-exercise resting levels, demonstrated the ability of both fluid treatments to bring about rapid shifts in plasma glucose concentrations. However, since there were marked and statistically significant differences in the peak glucose levels achieved during exercise, which persisted into the recovery period, it could be concluded that there were characteristic differences in the provision of carbohydrate supply associated with treatment $D$ which suggested a delayed plasma rise and reduced uptake of carbohydrate in comparison with treatment $Q$.

\section{DISCUSSION}

The physiological demand associated with trial $D$ was significantly greater than that of trial $Q$ in terms of the relative and absolute body weight (fluid) loss, as well as the cardiovascular responses to the standardised work task. Furthermore, the return to pre-exercise levels during the recovery period was enhanced by treatment Q. These responses were due largely to the differences in relative fluid volumes required to ensure the isocaloric energy provision of the fluid treatments involved, rather than qualititative differences between the fluids, thus confirming the importance of volume related effects (Costill and Saltin, 1974).

Whilst both treatments $D$ and $Q$ provided evidence 
TABLE III

Mean physiological changes during the experimental protocol

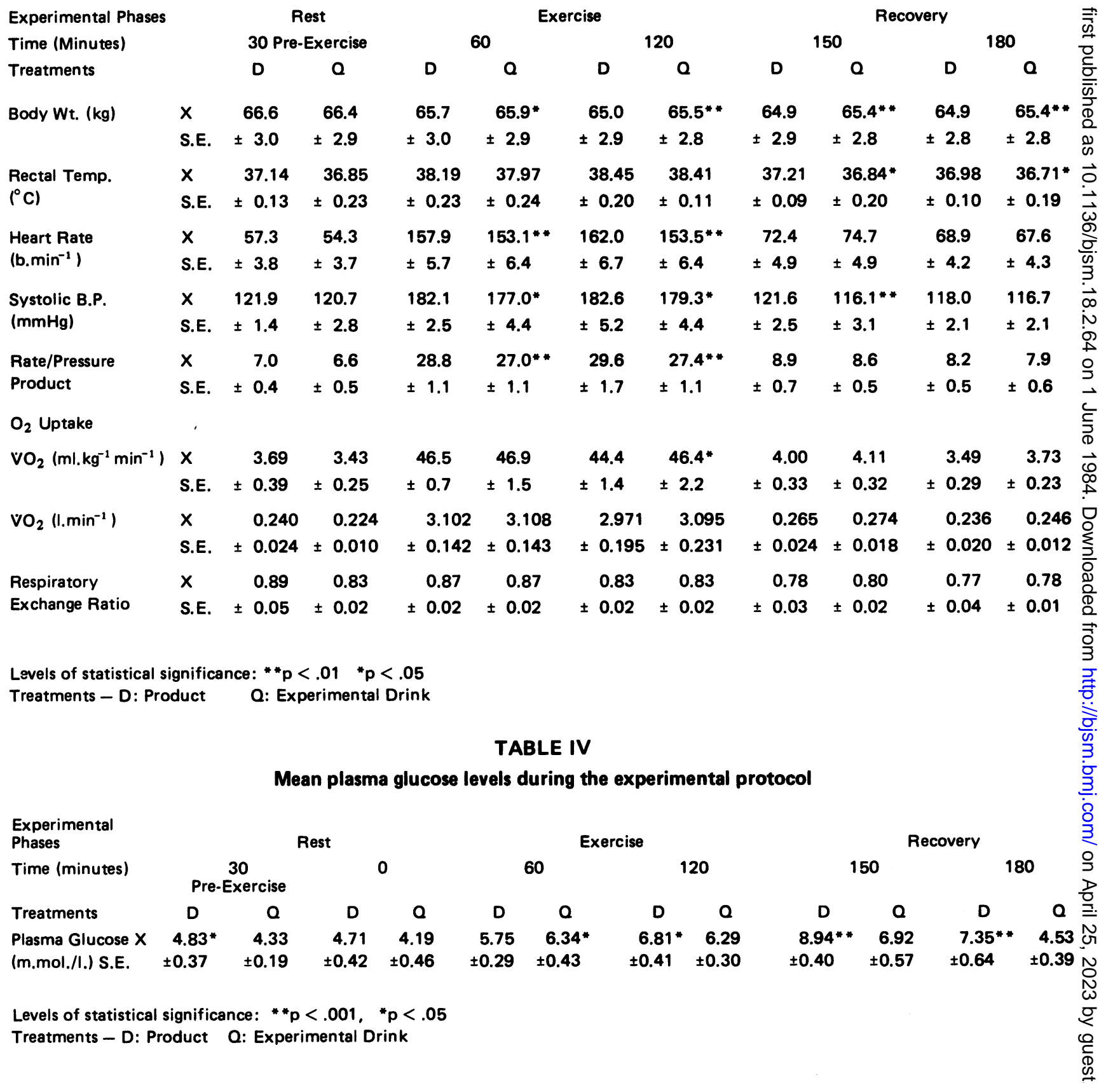

of carbohydrate maintenance capabilities during exer- This factor may have been responsible for the plateau cise, similar to that reported by other studies (Costill et al, 1970 Costill et al, 1973; Langenfield, 1983), the timing of carbohydrate loading favoured treatment $Q$, which was probably related to the influence of fluid volume on gastric emptying (Costill and Saltin, 1974). of plasma glucose levels observed during exercise in treatment 0 . Nevertheless, respective peak plasma glucose levels were delayed until the recovery period in both treatments $D$ and $Q$, but the fall in plasma levels during treatment $Q$, by the end of the recovery period, 
may have indicated that the rate of carbohydrate supply to the tissues favoured treatment $Q$. Nevertheless there was no indication of reactive hypoglycomic effects following exercise since plasma glucose levels remained above preexercise values in both formulations even after one hour recovery from strenuous exercise. In both treatments $D$ and $Q$ the maintenance of blood glucose homeostasis may have offset muscle glycogen depletion during exercise (Pirnay et al, 1977 a and b), thus facilitating work performance which has been reported elsewhere (Ivy et al, 1983). The characteristic differences of timing and pattern, in the provision of carbohydrate supply associated with the two treatments, must be further considered following the subjective assessment by the experimental subjects which indicated a preference for treatment $Q$ (a citrous drink) versus treatment $D$ (a glucose syrup), because it was palatable. The findings relating to the effect of the experimental formulation (Q) confirms previous results from this laboratory concerning the ability of the product formulation (D) to increase plasma carbohydrate levels during exercise (Brooke et al, 1972; Brooke and Green, 1973; Brooke and Green, 1974; Brooke et al, 1975). However the results suggest that the experimental formulation has considerably enhanced properties in comparison with the product formulation.

\section{ACKNOWLEDGEMENTS}

The investigation was supported by a grant from Beecham Products Limited, Research and Development Division, and technical support was received from the Clinical Biochemistry Laboratory of Hope Hospital, Salford. Additional assistance was provided by $\mathrm{Mr}$. $\mathrm{H}$. Nelson (Coaching), and Mr. J. Mulhall and Dr. M. Al-Dawalibi (Human Performance Laboratory, Salford University). Finally, the authors would like to thank the cyclists involved who underwent such a prolonged and exhausting series of trials.

\section{REFERENCES}

Ahlborg, G. and Felig, P., 1977 "Substrate utilisation during prolonged exercise preceded by ingestion of glucose". Amer.J.Physiol. 230: E188-E194.

Bergström, J. L., Hermansen, L., Hultman, E. and Saltin, B., 1967 “Diet muscle glycogen and physical performance". Acta Physiol.Scand. 71: 140-150.

Bergström, J. and Hultman, E., 1972 “Nutrition for maximal sports performance”. J.Amer.Med.Assoc. 221: 999-1003.

Brooke, J. D., Davies, G. J. and Green, L. F., 1972 "Nutrition during severe prolonged exercise in trained cyclists". Proc.Nutr.Soc. 31: 93A.

Brooke, J. D. and Green, L. F., 1973 "Variations in available carbohydrate and physical work ability with repeated prolonged severe exercise". Proc.Nutr.Soc. 32: 11A.

Brooke, J. D. and Green, L. F., 1974 "The effect of a high carbohydrate diet on human recovery following prolonged work to exhaustion". Ergonomics 17 (4): 489-497.

Brooke, J. D., Davies, G. J. and Green, L. F., 1975 "The effect of normal and glycose syrup work diets on the performance of racing cyclists". J.Sports Med.Phys.Fit. 15 (3): 257-265.

Brooke, J. D. and Green, L. F., 1975 "Effect of close and open spaced work trials upon endurance and body carbohydrate stores in trained endurance sportsmen". J.Sports Med.Phys.Fit. 15 (2): 91-99.

Costill, D. L., Kammer, W. F. and Fischer, M. A., 1970 "Fluid ingestion during distance running". Arch.Environ. Health 21: 520-525.

Costill, D. L., Bennett, A., Branam, G. and Eddy, D., 1973 "Glucose ingestion at rest and during prolonged exercise". J. Appl.Physiol. 34 (6): 764-769.

Costill, D. L. and Saltin, B., 1974 "Factors limiting gastric emptying during rest and exercise". J.Appl.Physiol. 37: 679-683.

Crapo, P. A., Reavan, G. and Olefsky, J., 1976 "Plasma glucose and insulin responses to orally administered simple and complex carbohydrates". Diabetes 25: 741-747. 
Fordtran, J. S. and Saltin, B., 1967 "Gastric emptying and intestinal absorption during prolonged severe exercise". J.Appl.Physiol. 23 (3): 331-335.

Foster, C., Costill, D. L. and Fink, W. J., 1979 "Effects of pre-exercise feedings on endurance performance". Med.Sci. Sports 11: 1-5.

Green, L. F. and Thomas, V., 1971 "Some effects of glycose syrup ingestion during vigorous exercises of different intensities and duration". Proc.Nutr.Soc. 31: 5A.

Green, L. F., 1976 "A comparison of two glucose syrup drinks with D-glucose monohydrate solutions as a test-load in the glucose tolerance test". Fed.Chem. 1: 67-77.

Ivy, J. L., Costill, D. L., Fink, W. J. and Lower, R. W., 1979 “Influence of caffeine and carbohydrate feedings on endurance performance". Med.Sci.Sports 11: 6-11.

Ivy, J. L., Miller, W., Dover, V., Goodyear, L. G., Sherman, W. M., Farrell, S. and Williams, H., 1983 "Endurance improved by ingestion of a glucose polymer supplement". Med.Sci.Sports and Exer. 15: 466-471.

Langenfield, M. E., 1983 “Glucose polymer ingestion during ultra-endurance bicycling”. Res.Quart.Exer.Sport.

Pirnay, F., Lacroix, M., Mosora, F., Luyclex, A. and Lefebvre, P., 1977a "Effect of glucose ingestion on energy substrate utilisation during prolonged muscular exercise". Euro.J.Physiol. 36: 247-254.

Pirnay, F., Lacroix, M., Mosora, F., Luyclex, A. and Lefebvre, P., 1977b "Glucose oxidation during prolonged exercise evaluated with naturally labelled 13c glucose". J.Appl.Physiol. 43: 258-261.

Thomas, V., 1971 "Some effects of glucose syrup ingestion upon extended sub-maximal sports performance". Brit.J. Sports Med. 5: 212-215.

White, J. A. and Ford, M. A., 1983 "The hydration and electrolyte maintenance properties of an experimental sports drink". Brit.J.Sports Med. 17: 51-58.

\section{BOOK REVIEW}

Title: $\quad$ INFERENTIAL THERAPY

Author: Brenda Savage, MSc, MCSP, DipTP

Publisher: $\quad$ Faber \& Faber, London

Price:

This little book is a very useful extra for the physiotherapist's library. It has been long needed ( - the only other book, to my knowledge, is produced by one of the medical companies, and is very expensive).

The chapter on physical principles of interferential therapy is very explicit, and the other chapters are useful references for recent injuries, rheumatic conditions, shoulders and back pain, and other more obscure problems.

There is a section on suggested treatment regimes - being very helpful to physiotherapists 'new' to interferential therapy.

The diagrams are very clear, but the photographs are unfortunately not so - which spoils it a little. In all certainly worth buying for reference.

Paula Willcock, MCSP 